\title{
Genomic change of chromosome 8 predicts the response to taxane-based neoadjuvant chemotherapy in node-positive breast cancer
}

\author{
SEHWAN HAN ${ }^{1}$, KYEONGMEE PARK $^{2}$, EUNAH SHIN $^{2}$, HYUN-JUNG KIM $^{2}$, \\ JUNG YEON KIM ${ }^{2}$, JI YOUNG $\mathrm{KIM}^{3}$ and GEUMHEE GWAK ${ }^{1}$ \\ Departments of ${ }^{1}$ Surgery, ${ }^{2}$ Pathology, and ${ }^{3}$ Radiology, Inje University Sanggye Paik Hospital, Seoul, Korea \\ Received November 11, 2009; Accepted April 6, 2010
}

DOI: 10.3892/or_00000836

\begin{abstract}
This study was performed to investigate whether the response to neoadjuvant chemotherapy in ductal-type breast cancer could be predicted by different genomic alterations. Array-based comparative genomic hybridization $(\mathrm{aCGH})$ was performed on samples from 15 patients who underwent neoadjuvant chemotherapy with epirubicin plus docetaxel (ED). Frozen tissue bank samples were retrospectively selected from 8 patients who demonstrated complete pathologic response (pCR) and from 7 patients resistant to neoadjuvant chemotherapy. We performed aCGH with 4,277 human bacterial artificial chromosome (BAC) clones, scanning the genome for DNA copy number changes. In a cluster dendrogram of aCGH data, responders showed changes clustered in S940, S984, S44, S98, S130, S115, S478, and $1150 \mathrm{~T}$, whereas non-responder group changes clustered in S1029, S209, S219, S660, S133, S323, and S670. Compared to responders, non-responders showed more complicated genomic alterations; the most common gains were located at chromosome 8q (71\%), 13q (71\%), and 20q (57\%), with the smallest regions of genomic gain at 8q24.3, 8q24.22, $8 \mathrm{q} 24.21,8 \mathrm{q} 22.1,8 \mathrm{q} 22.2,8 \mathrm{q} 22.3,13 \mathrm{q} 21.1,20 \mathrm{q} 13.2$, and 20q13.33. The most frequently deleted regions were observed on chromosome $8 \mathrm{p}(71 \%)$ and $17 \mathrm{p}(57 \%)$, with the smallest regions of deletion at $8 \mathrm{p} 23.3,8 \mathrm{p} 23.2,8 \mathrm{p} 23.1,8 \mathrm{p} 21.3$, $8 \mathrm{p} 21.2$, and $17 \mathrm{p} 13.3$. The results of the current study suggest that aberrations in chromosome 8 may contribute to the resistance to taxane-based neoadjuvant chemotherapy in ductal-type breast cancer. Results of our study indicate that candidate gene identification through aCGH should be validated by specific gene analysis since the sites of chromosomal aberration are quite different among studies.
\end{abstract}

Correspondence to: Dr Kyeongmee Park, Department of Pathology, Inje University Sanggye Paik Hospital, 761-1, Sanggye-dong, Nowon-gu, 139-707 Seoul, Korea

E-mail: kpark@paik.ac.kr

Key words: array-based comparative genomic hybridization, breast cancer, chemotherapy, response

\section{Introduction}

Breast cancer, the most common cancer in women worldwide, is a complex and intrinsically heterogeneous disease. Most patients with breast cancer tend to exhibit similar clinical features despite entirely different genetic backgrounds. While vast improvements have been made in diagnosis and treatment of this disease, clinical outcome of most patients have not dramatically improved. Due to the lack of reliable predictors for the response of specific treatment, many women at low risk of disease progression are unnecessarily subjected to aggressive systemic therapies, while those at high risk develop resistance to cytotoxic treatment in a rather short period even after systemic therapy. To establish efficient and more individualized therapy, better understanding for the biologic characteristics of breast cancer is a prerequisite step.

The introduction of multigene assay technologies using DNA microarrays has expanded our knowledge on genetic phenomena associated with breast cancer. However, the utility of gene expression studies has been limited by the identification of different candidate genes in different studies. Most multigene studies have concentrated on identifying high-risk patients who are more likely to have recurrent breast cancer after standard systemic treatment. Breast cancer progression is due to the accumulation of multiple genomic alterations that lead to growth advantages and clonal expansion, and these genomic alterations appear to be associated with the prognosis of individual patients (1). Such genetic alterations are important steps in the development of human malignancies, and may contribute both to disease progression and to responses to specific treatments. After the introduction of DNA microarray technology, several studies were performed to integrate gene expression profiles with the outcomes of specific cytotoxic treatments. Until now, no study has identified gene expression profiles that explain responses to specific chemotherapy.

Array-based comparative genomic hybridization (aCGH) offers a unique opportunity to identify those genes related to tumor development and progression (2). The routine use of aCGH profiles has been proposed to classify a disease into clinically relevant subgroups, with implications for the prognosis and treatment of breast cancer (3-6). Several attempts have been made to correlate patterns of genomic change 
detected by aCGH with breast cancer prognosis $(3,6-21)$. aCGH profiles have been successfully applied to identify new oncogenes and tumor suppressor genes that may be promising therapeutic targets $(22,23)$. In the present study, we performed aCGH with frozen core needle biopsy samples of primary breast cancer and profiled the genetic changes associated with responses to docetaxel-based neoadjuvant chemotherapy.

\section{Materials and methods}

Study design and selection of patients. Patients with locally advanced breast cancer (i.e., primary cancers $>4 \mathrm{~cm}$, or clinically evident axillary metastases) diagnosed at Inje University Sanggye Paik Hospital between 2002 and 2007 were included in this study. Prior to neoadjuvant chemotherapy, we collected five or six core biopsies of the primary breast cancer in each patient. Three core biopsy specimens were immediately cryopreserved at $-80^{\circ} \mathrm{C}$ for later analysis. The remaining specimens were fixed in formalin for diagnostic analysis and immunohistochemical staining.

Clinicopathologic variables including tumor size, histologic grade, and hormone receptor status were determined before chemotherapy. We administered four cycles of neoadjuvant chemotherapy with epirubicin $75 \mathrm{mg} / \mathrm{m}^{2}$ plus docetaxel $100 \mathrm{mg} / \mathrm{m}^{2}$ at 3-week intervals, and assessed the clinical response after completion of the fourth cycle. As part of standard care, patients underwent chemotherapy for four cycles, unless clear evidence existed of progressive disease, defined as an increase in tumor size of more than $25 \%$. After the completion of neoadjuvant chemotherapy, curative surgery was performed. Pathologic complete response (pCR) was defined as the disappearance of all invasive cancer in the breast after completion of neoadjuvant chemotherapy.

This study was conducted under the approval of the institutional review board of Inje University Sanggye Paik Hospital. Frozen tissue samples were selected retrospectively from a tissue bank belonging to 8 patients who demonstrated complete pathologic response (pCR) and 7 patients who were resistant to neoadjuvant chemotherapy.

Bacterial artificial chromosome (BAC) library. Bacterial artificial chromosome (BAC) clones were selected from Macrogen's proprietary BAC library (http://www.macrogen. com). Briefly, pECBAC1 (24) was restricted with HindIII, and size-selected HindIII-digested pooled male DNA was used to generate a BAC library. The vectors containing this library were transformed into and maintained in DH10B.

Construction of a BAC-mediated aCGH microarray. Clones were first selected bioinformatically to give an average genomic coverage of $1 \mathrm{Mb}$ resolution. All of the clones were end-sequenced using Applied Biosystems 3700 sequencers, and their sequences were blasted and mapped to their chromosomal positions using the UCSC human genome database (http://www.genome.uscs.edu). Confirmation of locus specificity of the chosen clones was performed by removing multiple loci-binding clones and examining them individually under standard fluorescence in situ hybridization (FISH) conditions, as previously described (25). BAC clone DNA was prepared by conventional alkaline lysis and sonicated to generate fragments approximately $3 \mathrm{~kb}$ in length, before mixing with $50 \%$ dimethyl sulfoxide (DMSO) spotting buffer. Arrays were manufactured by Genomic Solutions using an OmniGrid 100 spotter. Each clone was represented on an array by duplicated spots, and each array was prescanned using a GenePix4200A scanner (Axon Instrument, Sunnyvale, CA, USA) for proper spot morphology. The array used in this study consisted of 4,362 human BAC clones.

DNA labeling for aCGH. Labeling and hybridization protocols used were as described by Pinkel et al, with some modification to the labeling procedure (23). Briefly, $2 \mu \mathrm{g}$ of test and reference DNAs were digested overnight with Dpn II. After purification, $21 \mu 1$ containing $800 \mathrm{ng}$ of digested normal DNA (reference) or digested tumor DNA (test) and $20 \mu 1$ BioPrime ${ }^{\circledR}$ Array CGH Genomic Labeling System Random primer solution (Invitrogen, Carlsbad, CA, USA) in water were combined and incubated for $5 \mathrm{~min}$ at $95^{\circ} \mathrm{C}$, and subsequently cooled on ice. After the addition of $5 \mu 1$ 10x dNTP labeling mix (0.6 mM dCTP, $1.2 \mathrm{mM}$ dATP, $1.2 \mathrm{mM}$ dGTP, $1.2 \mathrm{mM}$ dTTP), $3 \mu 11 \mathrm{mM} \mathrm{Cy3}$ or Cy5-dCTP (Perkin Elmer, Waitham, MA, USA), and $40 \mathrm{U}^{\mathrm{BioPrime}}{ }^{\circledR}$ Array CGH Genomic Labeling System Exo-Klenow fragment (Invitrogen), the mixture was gently mixed and incubated for $16 \mathrm{~h}$ at $37^{\circ} \mathrm{C}$. The addition of $5 \mu 1$ BioPrime $^{\circledR}$ Array CGH Genomic Labeling System Stop Buffer (Invitrogen) ended the reaction. After labeling, unincorporated fluorescent nucleotides were removed using a purification module (Invitrogen). In one tube, Cy3-labeled sample and Cy5-labeled reference DNAs were mixed together, and $100 \mu \mathrm{g}$ of human Cot I DNA (Invitrogen), $30 \mu 13 \mathrm{M}$ sodium acetate, and $600 \mu \mathrm{l}$ cold $100 \%$ ethanol were added to precipitate the DNA.

Array hybridization, imaging, and data analysis. Labeled DNA pellets were resuspended in $40 \mu 1$ hybridization solution containing $50 \%$ formamide, $10 \%$ dextran sulfate, 2 x SSC, $4 \%$ SDS, and $200 \mu \mathrm{g}$ yeast tRNA. The hybridization solution was denatured for $10 \mathrm{~min}$ at $70^{\circ} \mathrm{C}$ and incubated subsequently for $1 \mathrm{~h}$ at $37^{\circ} \mathrm{C}$ to allow blocking of repetitive sequences. Hybridizations were performed in slide chambers for $48 \mathrm{~h}$ at $37^{\circ} \mathrm{C}$. After post-hybridization washes, arrays were rinsed, dried by centrifugation, and scanned, generating two 16-bit TIFF image files for each array, using a GenePix4200A two-color fluorescent scanner (Axon Instrument).

Validation of genomic changes by fluorescence in situ hybridization (FISH). To confirm specific gains and losses of BAC clones observed in the aCGH analyses, FISH was performed using individual BAC clones as probes on isolated nuclei from tumor sections. The gene loci examined corresponded to overrepresented or deleted BAC clones, using appropriate centromeric probes as controls. FISH was performed at selected loci (WISP1 and NDRG1, 8q24.22) from 15 tumors to validate the copy number changes identified by aCGH. Target probe labeled with $\mathrm{Cy} 3$ was mixed with the same quantity of 2 BAC clones (Macrogen, Seoul, Korea) of no. 359 and no. 21 on 8q24.22 region. Control probe labeled with FITC was made by the same method with 4 BAC clones (Macrogen) of no. 7443, no. 7444, 149_F07 and 28_B06 on $8 \mathrm{q} 11.1$ region. Target probe size is $\sim 202.6 \mathrm{~kb}$ and control probe size is $\sim 211.6 \mathrm{~kb}$. For HER2 gene, PathVysion (Vysis 
Table I. Clinicopathological characteristics of 15 patients with node-positive invasive ductal carcinoma.

\begin{tabular}{|c|c|c|c|c|c|c|c|}
\hline & $\mathrm{HG}$ & NG & ER & PR & HER2 & Ki67LI & Size $(\mathrm{cm})$ \\
\hline SD1 & 3 & 1 & + & + & + & 30 & 10 \\
\hline SD2 & 3 & 1 & - & - & - & 30 & 6 \\
\hline SD3 & 3 & 1 & - & - & - & 50 & 7 \\
\hline SD4 & 2 & 2 & - & - & - & 5 & 7 \\
\hline SD5 & 2 & 2 & + & + & - & 30 & 15 \\
\hline SD6 & 2 & 2 & + & + & - & 20 & 5 \\
\hline SD7 & 3 & 1 & - & - & - & 90 & 7 \\
\hline pCR1 & 3 & 1 & + & + & + & 30 & 4 \\
\hline pCR2 & 3 & 1 & + & - & + & 30 & 4 \\
\hline pCR3 & 2 & 2 & + & + & + & 5 & 3 \\
\hline pCR4 & 3 & 1 & - & - & + & 20 & 3 \\
\hline pCR5 & 3 & 1 & + & + & + & 40 & 3 \\
\hline pCR6 & 2 & 2 & + & + & - & 10 & 4 \\
\hline pCR7 & 2 & 2 & + & + & - & 10 & 5 \\
\hline pCR8 & 3 & 1 & + & - & - & 20 & 7 \\
\hline
\end{tabular}

HG, Bloom-Richardson's histologic grade; NG, Black's nuclear grade; ER, estrogen receptor; PR, progesterone receptor; Ki67LI, Ki67 labeling index; $\mathrm{SD}$, stable disease; $\mathrm{pCR}$, pathological complete response.

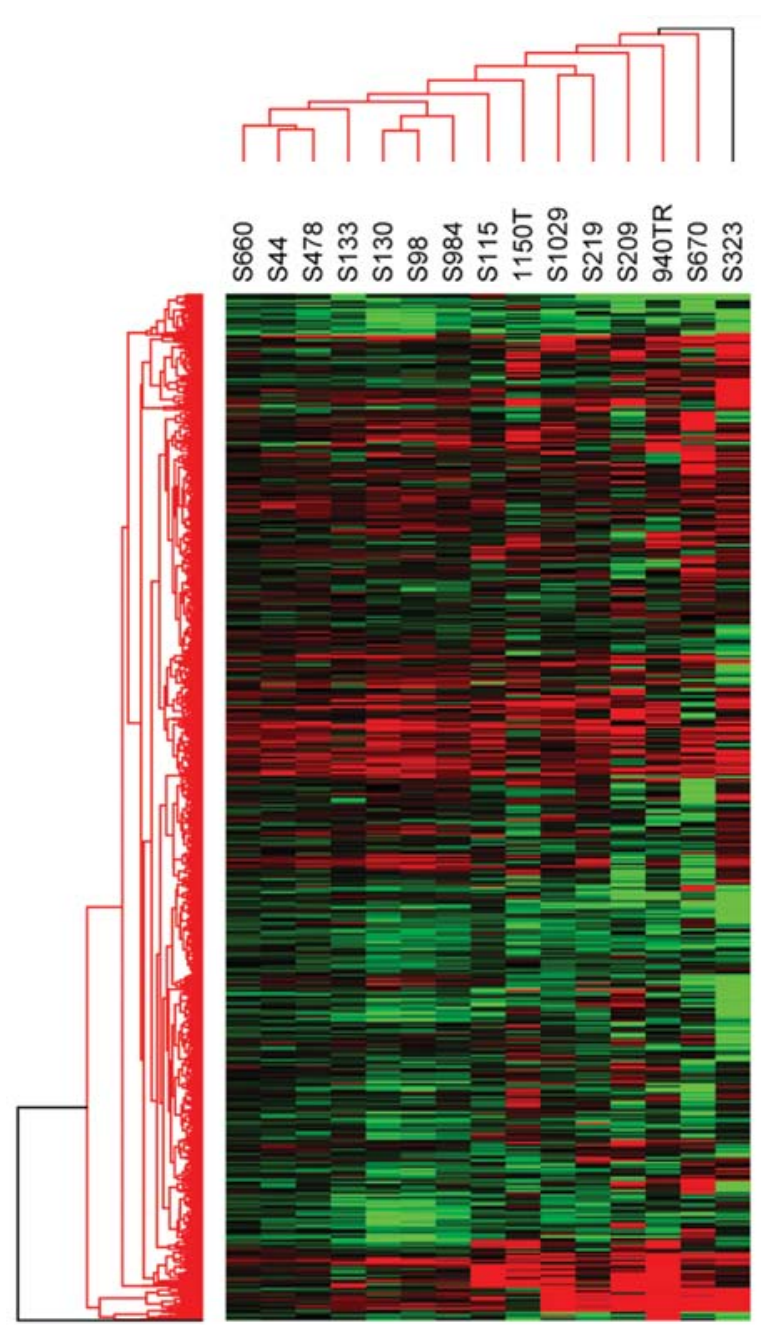

Figure 1. Cluster dendrogram of array CGH data from 15 node-positive invasive ductal carcinomas by unsupervised clustering. The samples from the response and non-response group reveal distinct cluster formation (response group: S44, S478, S130, S98, S984, S115, 1150T; no response group: S660, S133, S1029, S219, S209, S670, S323).
Inc., Downers Grove, IL, USA) was applied. Four- $\mu$ m-thick sections from paraffin blocks were deparaffinized, dehydrated, immersed in $0.2 \mathrm{~N} \mathrm{HCl}$ for $20 \mathrm{~min}$ at room temperature and incubated in $1 \mathrm{~mol} / 1 \mathrm{NaSCN}$ for $35 \mathrm{~min}$ at $80^{\circ} \mathrm{C}$. Slides were immersed in pepsin solution (Vysis) for $20 \mathrm{~min}$ at $37^{\circ} \mathrm{C}$, and tissues were fixed by $10 \%$ neutral buffered formalin. Dual probes for hybridization was performed according to the manufacturer's protocol. The probes and target DNA were simultaneously denatured. Ten microliters of the probe mixture was applied to slides, which were incubated in a humidified atmosphere with Hybrite (Vysis) for $16 \mathrm{~h}$ at $37^{\circ} \mathrm{C}$ in the dark. Slides were immersed in $0.4 \mathrm{x} \mathrm{SSC} / 0.3 \% \mathrm{NP}-40$ for $20 \mathrm{~min}$ at room temperature, and then in $2 \mathrm{xSSC} / 0.1 \% \mathrm{NP}-40$ for $5 \mathrm{~min}$ at $73^{\circ} \mathrm{C}$. After drying, nuclei were counterstained with 4,6diamidino-2-phenylindole (DAPI) and antifade compound (P-phenylenediamine). The marker (orange) and control (green) signal ratio was calculated and twice as many marker signals than control signals were considered as the criteria for gene amplification.

Data processing and analysis. The average fluorescence ratio of the two replicate spots for each clone was calculated. Clones with missing values (81 clones) and sex chromosomes (286 clones) were excluded; 3,991 different BAC clones were used in the final analysis. The $\log 2$-transformed fluorescent ratios were calculated from background-subtracted mean intensity values. These ratios were used to perform print-tip normalization before copy number calculations. The purpose of normalization is to adjust for effects that arise from variation between the red and green dyes or from scanner settings for the two fluors. $\mathrm{R}$ and $\mathrm{G}$ indicate the background-corrected Cy5 and $\mathrm{Cy} 3$ intensities for each spot, respectively. Normalization is usually applied to the $\log$ ratios of $\mathrm{Cy} 3$ and $\mathrm{Cy} 5$, which will be written as $\mathrm{M}=\log \mathrm{R}-\log \mathrm{G}$. The $\log$ intensity of each spot is written as $A=(\log R+\log G) / 2$. The $M$-value is normalized by subtracting from it the corresponding value of the print-tip group LOWESS curve. The normalized $\log$ ratios $\mathrm{N}$ are the 
Table II. Most significant genomic aberrations in no response group in 15 node-positive invasive ductal carcinomas.

\begin{tabular}{|c|c|c|c|}
\hline Gain & Representative genes & Frequency $(\%)$ & P-value \\
\hline $8 \mathrm{q} 22.1$ & & 71 & 0.0468 \\
\hline $8 \mathrm{q} 22.2$ & KCNS2, STK3 & 71 & 0.0468 \\
\hline $8 \mathrm{q} 22.3$ & & 71 & 0.0468 \\
\hline $8 \mathrm{q} 24.12$ & MRPL13, MTBP, SNTB1 & 71 & 0.0468 \\
\hline $8 \mathrm{q} 24.21$ & DDEF1, DDEF1IT1 & 71 & 0.0468 \\
\hline $8 \mathrm{q} 24.21$ & & 1 & 0.0468 \\
\hline $8 \mathrm{q} 24.22$ & TG & 71 & 0.0468 \\
\hline $8 \mathrm{q} 24.22$ & WISP1, NDRG1 & 71 & 0.0468 \\
\hline $8 \mathrm{q} 24.22$ & WISP1, NDRG1 & 71 & 0.0468 \\
\hline $8 \mathrm{q} 24.3$ & & 71 & 0.0468 \\
\hline $8 \mathrm{q} 24.3$ & LYPD2, LYNX1, LY6D, GML, LOC646338 & 71 & 0.0468 \\
\hline $8 \mathrm{q} 24.3$ & $\begin{array}{l}\text { CYHR1, KIFC2, FOXH1, PPP1R16A, GPT, } \\
\text { MFSD3, RECQL4, LRRC24, MGC70857, KIAA1688 }\end{array}$ & 71 & 0.0468 \\
\hline $8 \mathrm{q} 24.3$ & $\begin{array}{l}\text { CYHR1, KIFC2, FOXH1, PPP1R16A, GPT, MFSD3, } \\
\text { RECQL4, LRRC24, MGC70857, KIAA1688 }\end{array}$ & 71 & 0.0468 \\
\hline $13 \mathrm{q} 21.1$ & $\begin{array}{l}\text { FLJ40296, LOC729233, LOC729240, LOC729246, } \\
\text { LOC729250 }\end{array}$ & 71 & 0.0081 \\
\hline $20 \mathrm{q} 13.2$ & & 57 & 0.0295 \\
\hline $20 q 13.33$ & & 43 & 0.0295 \\
\hline \multicolumn{4}{|l|}{ Loss } \\
\hline $8 \mathrm{p} 23.3$ & LOC389607, ERICH1 & 71 & 0.0081 \\
\hline $8 \mathrm{p} 23.3$ & C8orf68 & 57 & 0.0295 \\
\hline $8 \mathrm{p} 23.3$ & & 1 & 0.0468 \\
\hline $8 \mathrm{p} 23.2$ & CSMD1 & 71 & 0.0468 \\
\hline $8 \mathrm{p} 23.1$ & MSRA & 57 & 0.0295 \\
\hline $8 \mathrm{p} 21.3$ & DOK2, XPO7 & 57 & 0.0295 \\
\hline $8 \mathrm{p} 21.2$ & DOCK5, GNRH1, KCTD9, CDCA2 & 71 & 0.0081 \\
\hline $17 \mathrm{p} 13.3$ & RPH3AL & 57 & 0.0295 \\
\hline
\end{tabular}

residuals from the print-tip group LOWESS regression, i.e., $\mathrm{N}=\mathrm{M}$ - lowess (A), where lowess (A) is the LOWESS curve as a function of $\mathrm{A}$ for the ith print-tip group. Each LOWESS curve is constructed by performing a series of local regressions, one for each point in the scatterplot.

Chromosomal aberrations were categorized as a gain when the normalized $\log 2$-transformed fluorescent ratio was higher than 0.25 and as a loss when this ratio was below -0.25 . These two threshold values were chosen empirically by selecting a $3 \mathrm{xSD}$ value calculated from 30 normal male to normal female hybridization experiments. After calling loss, gain, and normal loci in the aCGH data, we performed $\chi^{2}$ tests using the counts of abnormality (loss, gain) versus normal. We then determined the adjusted p-values (FDR <0.05) from the R package of Bioconductor. Macrogen's MAC viewer aCGH analysis software was used for quantification and image analysis of aCGH data.

\section{Results}

Patient characteristics. The clinicopathological characteristics of 15 patients and their tumors are summarized in Table I.
All 15 patients received docetaxel-based neoadjuvant chemotherapy. Eight patients showed pCR and seven patients were resistant to neoadjuvant chemotherapy.

Genomic profiling. aCGH analysis was performed on 15 node-positive invasive ductal carcinoma core biopsies, which were all identified with high-resolution specific regions of gain and loss throughout the genome. A cluster dendrogram of aCGH data from the 15 biopsies was analyzed by unsupervised clustering (Fig. 1). The samples from the responder (pCR) and non-responder groups revealed distinct cluster formation. Responders clustered in S940, S984, S44, S98, $\mathrm{S} 130, \mathrm{~S} 115, \mathrm{~S} 478$, and 1150T, whereas non-responders clustered in S1029, S209, S219, S660, S133, S323, and S670. The eight patients of the responder group and the seven patients of the non-responder group were distinctly separated in the cluster dendrogram (Fig. 1).

All tumors showed genomic changes and the nonresponders revealed more complicated changes than responders in a $\log 2$ ratio plot of chromosomal copy number alterations (Fig. 2). Twenty-four clones that mapped to 16 different chromosome loci in five different chromosome arms were 

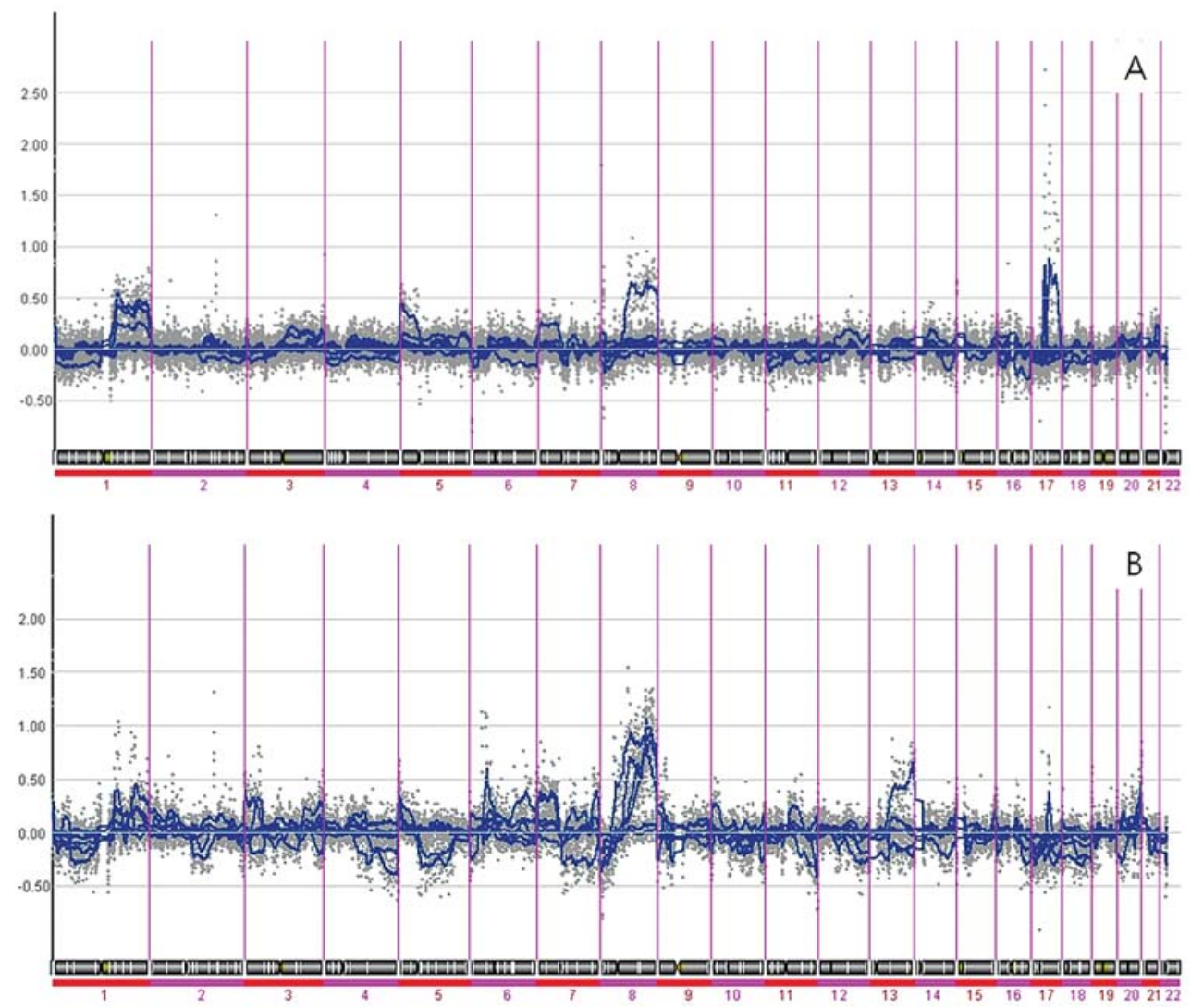

Figure 2. $\log 2$ ratio plot of response group (A) and no response group (B).
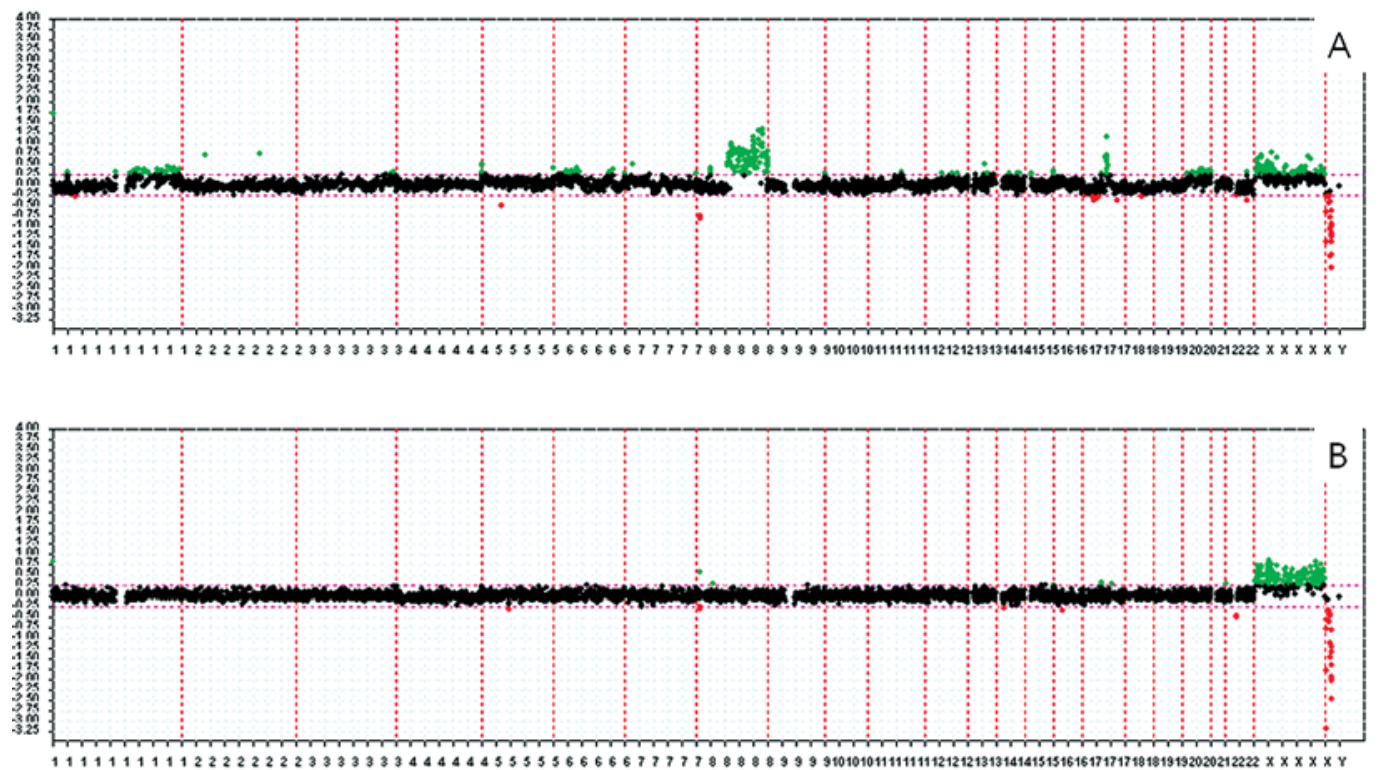

Figure 3. Scatter plot of no response group (A: S1029) and response group (B: S44). S1029 reveals chromosome 8q gain and 8p loss (log2 ratio mean 0.276, threshold: $0.25--0.25)$ and S44 reveals normal chromosome 8 ( $\log 2$ ratio mean -0.008 , threshol: $0.25--0.25)$.

identified. The chromosomal regions with the most common genomic alterations $(>40 \%)$ are shown in Table II. The most common gains corresponded to chromosome $8 \mathrm{q}(71 \%), 13 \mathrm{q}$ $(71 \%)$, and $20 \mathrm{q}(57 \%)$, with the smallest identified regions of genomic gain at 8q24.3, 8q24.22, 8q24.21, 8q22.1, 8q22.2,
$8 \mathrm{q} 22.3,13 \mathrm{q} 21.1,20 \mathrm{q} 13.2$, and $20 \mathrm{q} 13.33$. The region of 8q22.1-8q24.22 includes the genes KCNS2, STK3, MRPL13, MTBP, SNTB1, DDEF1, DDEF1IT1, TG, WISP1, NDRG1, LYNX1 , LY6D, GML, LOC646338, CYHR1, KIFC2, FOXH1, PPP1R16A, GPT, MFSD3, RECQL4, LRRC24, MGC70857, 


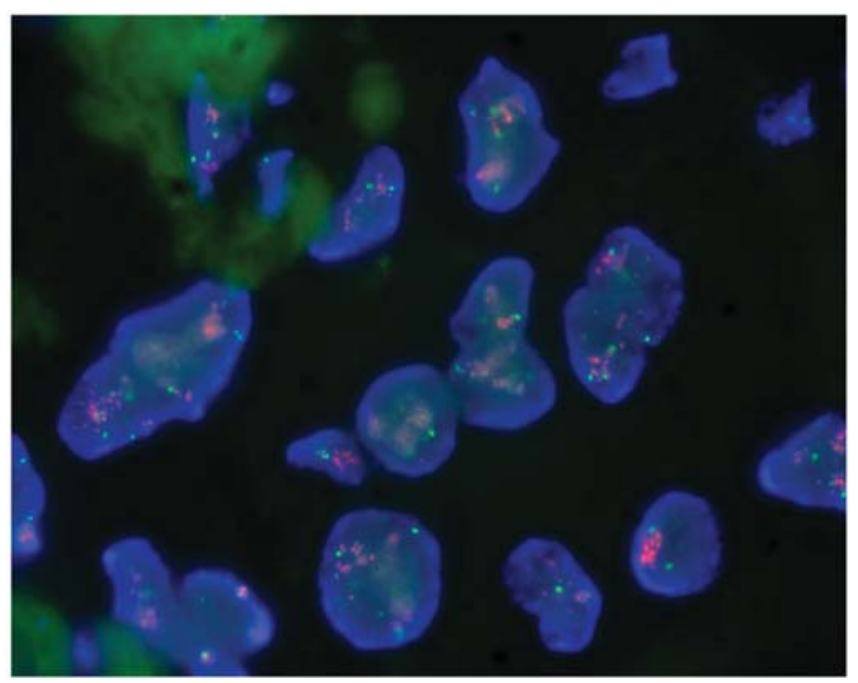

Figure 4. Amplification of WISP1 and NDRG1 was observed in the cases of 8q24.22 gain in aCGH. (Red signal: WISP1 and NDRG1; green signal: control, 8q11.1)

and KIAA1688. The most frequently deleted regions were observed at chromosome $8 \mathrm{p}(71 \%)$ and $17 \mathrm{p}(57 \%)$, with the smallest regions of deletion at $8 \mathrm{p} 23.3,8 \mathrm{p} 23.2,8 \mathrm{p} 23.1,8 \mathrm{p} 21.3$, $8 \mathrm{p} 21.2$, and $17 \mathrm{p} 13.3$. The region of $8 \mathrm{p} 21$ includes the genes DOK2, XPO7, DOCK5, GNRH1, KCTD9, and CDCA2, and 8p23 includes CSMD1, MSRA, LOC389607, ERICH1, and C8orf68 (Fig. 3).

FISH was performed on tumors to test selected genes. WISP 1 and NDRG 1 were chosen on the basis of aCGH results, and amplification of WISPI and NDRG1 were observed in the cases with gains in 8q24.22 (Fig. 4). HER2-overexpressing breast cancers showed gains at chromosome $17 \mathrm{q}$ (Fig. 5). Results of aCGH on 17q21 coincided well with the HER2 amplification confirmed by FISH in six patients. Of these patients, five responded to epirubicin plus docetaxel (ED) neoadjuvant chemotherapy.

\section{Discussion}

In the current study, most of the non-responders showed chromosomal gains in the $8 \mathrm{q}$ region compared to responders. Gains in $8 \mathrm{q}$ as well as $20 \mathrm{q}$ are known to be common in invasive ductal carcinomas and have been regarded as a poor prognostic indicator. In our study, patients with $8 \mathrm{q}$ gains responded poorly to ED neoadjuvant chemotherapy. Gains on $8 \mathrm{q}$ are known to be associated with higher proliferation rates, and this association is partly explained by c-myc-driven proliferation $(26,27)$. In our study, the most common gains were observed at $8 \mathrm{q} 24.3,8 \mathrm{q} 24.22,8 \mathrm{q} 24.21,8 \mathrm{q} 22.1,8 \mathrm{q} 22.2,8 \mathrm{q} 22.3,13 \mathrm{q} 21.1$, $20 \mathrm{q} 13.2$, and $20 \mathrm{q} 13.33$. The $8 \mathrm{q} 22-24$ region is close to that of c-myc, which is located at 8q24.1, but c-myc amplification was not observed in either group in our study. In a gene expression analysis of breast cancers, only two of eight tumors with c-myc amplification had increased expression of its mRNA (28). Another aCGH study also reported the absence of c-myc amplification (29), indicating that c-myc might not be the only target in the 8q24 amplicon in breast cancers. An association between poor response to neoadjuvant chemotherapy and $8 \mathrm{q}$ gain might be due to genes other than c-myc.

Candidate genes for gains in 8q22-24 are DDEF1, CCND1, and WISP1. The role of WISPI in breast cancer, however, is controversial. One study reported that WISP1 protein expression was reduced in advanced breast cancer compared to early stage disease (30). In contrast, other investigators reported that WISP1 protein expression was associated with an aggressive phenotype in breast cancer (31). Amplification of WISP1 was observed in the cases with gains in 8q24.22 and it was validated by FISH analysis. Clarifying the role of WISPI in breast cancer will require a further validation study. $D D E F 1$ amplification has been reported to be associated with highgrade melanoma, but a biological role of DDEF1 in breast cancer has not been reported (32).

Other studies combining CGH and expression profiles identified two candidate genes in the case of the 8q11-12 amplicon, FLJ14229 and SPFH2(C8org2) (33-35). However, we found no gains in 8q11-12 in the current study. The three studies were conducted on breast cancer tissues from Western women. An ethnic difference might exist in chromosomal aberration patterns of breast cancer. In our data, other putative genes responsible for genomic aberrations and implicated in breast cancer progression include $A I B 1$, which is located on 20q12, and CCND3 and P21/WAF on 6p21 (36). Gains in $20 \mathrm{q} 13$ were also demonstrated in our study. Amplification at $20 \mathrm{q} 13$ together with gains on 8p11-12 and 11q13-14 was correlated with poor prognosis in another study (6). Gains of $8 \mathrm{q}$ together with loss of $8 \mathrm{p}$ may represent the aggressive genotype of invasive breast cancer, although specific loci of chromosomal alterations differ among studies.

Our study showed that patterns of genomic alteration detected by aCGH differ between responders and non-

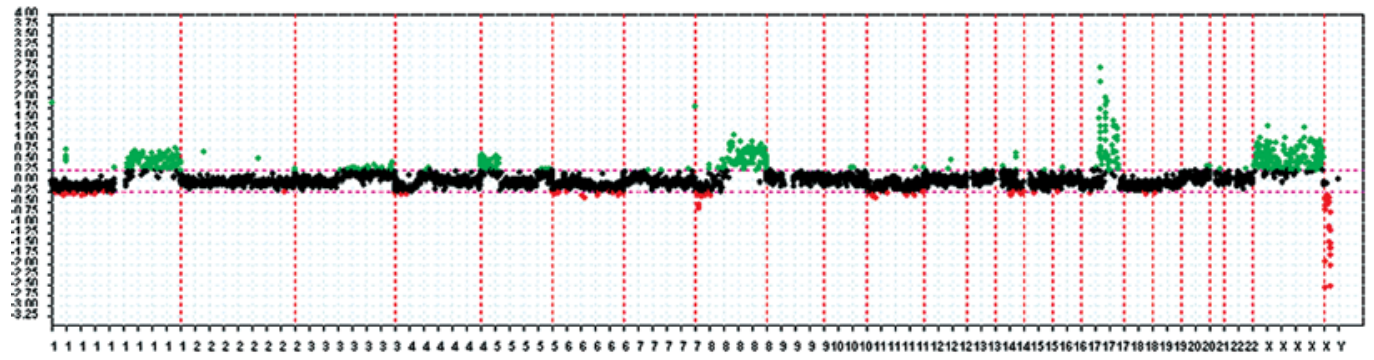

Figure 5. HER2 overexpressed breast cancer (threshold: $0.25--0.25$ ) showed chromosome 17q amplification in aCGH. 
responders to taxane-based chemotherapy. In our study, all the patients underwent four cycles of neoadjuvant ED chemotherapy. Thus, the therapeutic outcome could be influenced by the susceptibility of the tumors to anthracycline as well as to taxane. Amplification of topoisomerase II- $\alpha$ is a wellknown predictor of anthracycline sensitivity, and this association has been confirmed in large-cohort clinical trials. We have reported an intimate association between topoisomerase II- $\alpha$ amplification, which is almost always coamplified with HER2 and response to anthracycline-based neoadjuvant chemotherapy (37). We have also observed a close association between the amplification of HER2 and $c$-myc in breast cancer (38). In the current study, we observed a gain on 17q21 in four patients of the responder group, and topoisomerase II- $\alpha$ amplification by FISH coincided well with aCGH results. Aberrations in chromosomal sites other than $17 \mathrm{q}$, such as $8 \mathrm{q}$ and $8 \mathrm{p}$, might contribute to the resistance to docetaxel, although gains of 8q24 are common in ductal-type breast cancer.

In early breast cancer, patients with 11q deletion appeared to benefit from anthracycline-based adjuvant chemotherapy (4). However, we could not observe copy number aberration on $11 \mathrm{q}$ in the current study. A recent study reported that comparison of the pretreatment and the tumor specimens excised after neoadjuvant chemotherapy revealed genomic gains on 11p15.2-15.5 rather than 11q (39). The same investigators reported that loss of 13q31.1-32.2 were the only region to have significant difference between responders and non-responders to neoadjuvant chemotherapy with doxorubicin plus cyclophosphamide. In summary, the site of genomic aberration associated with response to neoadjuvant chemotherapy is different according to individual studies including our study. The three studies were performed on different patients regard to clinical characteristics and with different therapeutic regimens albeit all three contained anthracycline.

The goal of aCGH is to address relevant biological and clinical questions, such as the identification of genes responsible for carcinogenesis or cancer progression, and the prediction of clinical outcomes. Copy number aberrations are in many cases very large in area, making it difficult to determine how many genes are responsible for growth selection. Between 40 and $60 \%$ of the genes within an amplicon are believed to be overexpressed, but gene expression studies are needed to identify the genes responsible for any observed amplification. Validation study upon candidate genes identified by aCGH is mandatory since the genomic aberrations have found in quite different regions from studies to studies. However, specific chromosomal alterations can provide interesting clues to the identification of candidate genes, since these changes do not take place randomly in tumors, but represent preferential mutations of particular allelic forms.

In conclusion, the therapeutic response to taxane-based neoadjuvant chemotherapy apparently differed in accordance with gains on $8 \mathrm{q}$ and losses on $8 \mathrm{p}$. Our results indicate that genomic alteration patterns can be integrated into the prediction of response to docetaxel-based chemotherapy, although our conclusions are limited by a small sample size. The discrepancies of chromosomal aberration foci with other studies such as 8q11-12 and 11q suggest a possible ethnic difference of genetic changes of breast cancer between Western and Korean women. Results of our study indicates that candidate gene identification through aCGH should be validated by specific gene analysis since the sites of chromosomal aberration are quite different among studies.

\section{Acknowledgements}

This study was supported by Korea Research Foundation Grant (00042006033-00 and 00042007008-00) for K. Park.

\section{References}

1. Hanahan D and Weinberg RA: The hallmarks of cancer. Cell 100: 57-70, 2000.

2. Albertson DG and Pinkel D: Genomic microarrays in human genetic disease and cancer. Hum Mol Genet 2: R145-R152, 2003.

3. Climent J, Martinez-Climent JA, Blesa D, et al: Genomic loss of $18 \mathrm{p}$ predicts an adverse clinical outcome in patients with highrisk breast cancer. Clin Cancer Res 8: 3863-3869, 2002.

4. Climent J, Dimitrow P, Fridlyand J, et al: Deletion of chromosome 11q predicts response to anthracycline-based chemotherapy in early breast cancer. Cancer Res 67: 818-826, 2007.

5. Callagy G, Pharoah P, Chin SF, Sangan T, Daigo Y, Jackson L and Caldas $\mathrm{C}$ : Identification and validation of prognostic markers in breast cancer with the complementary use of arrayCGH and tissue microarrays. J Pathol 205: 388-396, 2005.

6. Chin K, Devries S, Fridlyand J, et al: Genomic and transcriptional aberrations linked to breast cancer pathophysiologies. Cancer Cell 10: 529-541, 2006.

7. Isola JJ, Kallioniemi OP, Chu LW, Fuqua SA, Hilsenbeck SG, Osborne CK and Waldman FM: Genetic aberrations detected by comparative genomic hybridization predict outcome in nodenegative breast cancer. Am J Pathol 147: 905-911, 1995.

8. Hermsen MA, Baak JP, Meijer GA, Weiss JM, Walboomers JW, Snijders PJ and van Diest PJ: Genetic analysis of 53 lymph node-negative breast carcinomas by $\mathrm{CGH}$ and relation to clinical, pathological, morphometric, and DNA cytometric prognostic factors. J Pathol 186: 356-362, 1998.

9. Jones C, Foschini MP, Chaggar R, Lu YJ, Wells D, Shipley JM, Eysebi V and Lakhani SR: Comparative genomic hybridizarion analysis of myoepithelial carcinoma of the breast. Lab Invest 80: 831-836, 2000

10. Fung LF, Wong $\mathrm{N}$, Tang $\mathrm{N}$, et al: Genetic imbalances in pT2 breast cancers of southern Chinese women. Cancer Genet Cytogenet 124: 56-61, 2001

11. Aubele M, Cummings M, Walsch A, Zitzelsberger H, Nahrig J, Hofler $\mathrm{H}$ and Werner M: Heterogeneous chromosomal aberrations in intraductal breast lesions adjacent to invasive carcinoma. Anal Cell Pathol 20: 17-24, 2000

12. Climent J, Garcia JL, Mao JH, Arsuaga J and Perez-Losada J: Characterization of breast cancer by array comparative genomic hybridization. Biochem Cell Biol 85: 497-508, 2007.

13. Dellas A, Torhorst J, Schultheiss E, Mihatsch MJ and Moch H: DNA sequence losses on chromosomes 11pand 18q are associated with clinical outcome in lymph node-negative ductal breast cancer. Clin Cancer Res 8: 1210-1216, 2002.

14. Hislop RG, Pratt N, Stocks SC, Steel CM, Sales M, Goudie D, Robertson A and Thompson AM: Karyotypic aberrations of chromosomes 16 and 17 are related to survival in patients with breast cancer. Br J Surg 89: 1581-1586, 2002.

15. Zudaire I, Odero MD, Caballero C, Valenti C, MartinezPenuela JM, Isola J and Calasanz MJ: Genomic imbalances detected by comparative genomic hybridization are prognostic markers in invasive ductal breast carcinomas. Histopathology 40: 547-555, 2002.

16. Cingoz S, Altungoz O, Canda T, Saydam S, Aksakoglu G and Sakizli M: DNA copy number changes detected by comparative genomic hybridization and their association with clinicopathologic parameters in breast tumors. Cancer Genet Cytogenet 145: 108-114, 2003.

17. Diallo R, Schaefer KL, Bankfalvi A, et al: Secretory carcinoma of the breast: a distinct variant of invasive ductal carcinoma assessed by comparative genomic hybridization and immunohistochemistry. Hum Pathol 34: 1299-1305, 2003. 
18. Janssen EA, Baak JP, Guervo MA, van Diest PJ, Jiwa M and Hermsen MA: In lymph node-negative invasive breast carcinomas, specific chromosomal aberrations are strongly associated with high mitotic activity and predict outcome more accurately than grade, tumor diameter, and oestrogen receptor. J Pathol 201: 555-561, 2003.

19. Weber-Mangal S, Sinn HP, Popp S, et al: Breast cancer in young women $(<$ or $=35$ years): Genomic aberrations detected by comparative genomic hybridization. Int J Cancer 107: 583-592, 2003 .

20. Jones C, Ford E, Gillet C, et al: Molecular cytogenetic identification of subgroups of grade III invasive ductal breast carcinomas with different clinical outcomes. Clin Cancer Res 10: 5988-5997, 2004.

21. Fridlyand J, Snijders AM, Ylstra B, et al: Breast tumor copy number aberration phenotypes and genomic instability. BMC Cancer 6: 96, 2006.

22. Pinkel D and Albertson DG: Array comparative genomic hybridization and its applications in cancer. Nat Genet 37 (Suppl.): S11-S17, 2005.

23. Pinkel D and Albertson DG: Comparative genomic hybridization. Annu Rev Genomics Hum Genet 6: 331-354, 2005.

24. Frijters ACJ, Zhang Z, van Damme M, Wang GL, Ronald PC and Michelmore RW: Construction of a bacterial artificial chromosome library containing large EcoRI and HindIII genomic fragments of lettuce. Theor Appl Genet 94: 390-399, 1997.

25. Do JH, Kim IS, Park TK and Choi DK: Genome-wide examination of chromosomal aberrations in neuroblastoma SH-SY cells by array-based comparative genomic hybridization. Moll Cells 24: 105-112, 2007.

26. Adhikary $\mathrm{S}$ and Eilers $\mathrm{M}$ : Transcriptional regulation and transformation by Myc proteins. Nat Rev Mol Cell Biol 6: 635-645, 2005.

27. Bergamaschi A, Kim YH, Wang P, Sorlie T, HernandezBoussard T, Lonning PE, Tibshirani R, Borresen-Dale AL and Pollack JR: Distinct patterns of DNA copy number alteration are associated with different clinicopathological features and gene-expression subtypes of breast cancer. Genes Chromosomes Cancer 45: 1033-1040, 2006.

28. Pollack JR, Sorlie T, Perou CM, et al: Microarray analysis reveals a major direct role of DNA copy number alteration in the transcriptional program of human breast tumors. Proc Natl Acad Sci USA 99: 12963-12968, 2002

29. Yao J, Weremowicz S, Feng B, Gentleman RC, Marks JR, Gelman R, Brennan $\mathrm{C}$ and Polak K: Combined cDNA array comparative genomic hybridization and serial analysis of gene expression analysis of breast tumor progression. Cancer Res 66 : 4065-4078, 2006.
30. Davies SR, Watkins G, Mansel RE and Jiang WG: Differential expression and prognostic implications of the CCN family members WISP-1, WISP-2, and WISP-3 in human breast cancer. Ann Surg Oncol 14: 1909-1918, 2007.

31. Xie D, Nakachi K, Wang H, Elashoff R and Koeffler P: Elevated levels of connective tissue growth factor, WISP-1 and CYR61 in primary breast cancers associated with more advanced features. Cancer Res 61: 8917-8923, 2001.

32. Ehlers JP, Worley L, Onken MD and Harbour JW: DDEF1 is located in an amplified region of chromosome $8 \mathrm{q}$ and is overexpressed in uveal melanoma. Clin Cancer Res 11: 3609-3613, 2005.

33. Ray ME, Yang ZQ, Albertson D, Kleer CG, Washburn JG, Macoska JA and Ethier SP: Genomic and expression analysis of the 8p11-12 amplicon in human breast cancer cell lines. Cancer Res 64: 40-47, 2004.

34. Prentice LM, Shadeo A, Lestou VS, et al: NRG1 gene rearrangements in clinical breast cancer: identification of an adjacent novel amplicon associated with poor prognosis. Oncogene 24: 7281-7289, 2005.

35. Garcia MJ, Pole JC, Chin SF, et al: A $1 \mathrm{Mb}$ minimal amplicon at 8p11-12 in breast cancer identifies new candidate oncogens. Oncogene 24: 5235-5245, 2005.

36. Nessling M, Richter K, Schwaenen C, Wrobel G, Wessendorf S, Fritz B, Bentz M, Sinn HP, Radlwimmer B and Lichter P: Candidate genes in breast cancer revealed by microarray-based comparative genomic hybridization of archived tissue. Cancer Res 65: 439-447, 2005.

37. Park K, Kim J, Lim S and Han S: Topoisomerase II-a (topoII) and HER2 amplification in breast cancers and response to preoperative doxorubicin chemotherapy. Eur J Cancer 39: 631-634, 2003.

38. Park K, Kwak K, Kim J, Lim S and Han S: c-myc amplification is associated with HER2 amplification and closely linked with cell proliferation in tissue microarray of nonselected breast cancers. Hum Pathol 36: 634-639, 2005.

39. Pierga JY, Reis-Filho JS, Cleator SJ, et al: Microarray-based comparative genomic hybridization of breast cancer patients receiving neoadjuvant chemotherapy. Br J Cancer 96: 341-351, 2007. 